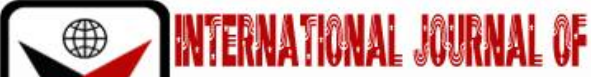

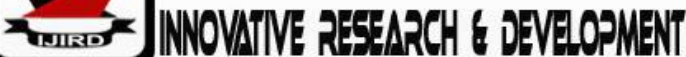

ISSN 2278-0211 (Online)

\section{Effect of Flag Diagram and Balance Model in Solving Linear Equations in One Variable: A Mixed Method Technique on First Year Senior High School Students}

\begin{tabular}{|c|}
\hline Yusif Zacharia \\
Tutor, Department of Mathematics and ICT, \\
Tumu College of Education, Ghana \\
Dennis Offei Kwakye \\
Tutor, Department of Mathematics and ICT, \\
Enchi College of Education, Ghana \\
Zunurain Zakari \\
Tutor, Department of Mathematics and ICT, \\
Methodist College of Education, Ghana
\end{tabular}

\begin{abstract}
:
This study investigated the effect of equation models, in the form of semi-concrete materials such as 'flag diagrams' and 'balance model', on first year senior high school students' ability to solve linear equations. Qualitative research methods such as interviews were employed. Quantitative data analysis techniques were used to analyse pre-test and post-test data of first year senior high school students who were in Visual Art One $(N=25)$. Paired samples $t$-test found statistically significant difference in favour of the post-test. The study found that the use of flag diagrams and balance model had positive effect on students' ability to solve linear equations in one variable, and also changed their perception and attitude towards learning of linear equations. The results indicated there is a strong evidence $(t=-10.821, p=0.000)$ that the teaching intervention improved the post-test scores. Participants experienced statistically significantly higher score in post-test $(p=0.000)$ when taught how to solve linear equations using the equation models $(M=12.9, S D=1.7)$ than in the pre-test $(M=5.12, S D=4.8)$. Differences in post-test scores, supported with qualitative data, suggested that the use of flag diagrams and balance model require more classroom time because of administrative issues, and because of time needed to learn how to use the models in addition to necessary time to learn mathematics content. Teachers must allow students enough time to develop conceptual understanding linking the flag diagrams and balance model to the mathematics represented. Additionally, a discussion of unique benefits and drawbacks of flag diagrams and balance model shed light upon the use of flag diagrams and balance model in senior high school mathematics. It is recommended that there should be a control group and an experimental group instead of an intact class.
\end{abstract}

Keywords: Equation model, flag diagram, balance model, linear equations in one variable, senior high school first year students

\section{Introduction}

\subsection{Background of the Study}

An equation is a mathematical statement that two things are equal. It consists of two expressions, one on each side of an 'equal' sign. In an equation, the left side is always equal to the right side. For example: $18=12+6$

An equation can also be described as a mathematical statement or a relation, which expresses the equality of two quantities [2]. An equation therefore involves the use of the 'equal' sign ' $=$ '. An equation can also be said to be a statement that is true for only a given real number of the variable in the statement. For example,

$3 x-2=10$

is true only when

$x=4$

Similarly, $a^{2}=9$

is an equation, since $a=3$

and $\quad a=-3$ 
In mathematics for teacher training in Ghana [30], it is stated that an equation is a mathematical sentence which shows that one quantity is equal to another quantity separated by an 'equal' sign. For example, the mathematical statement $x+12=17$

shows that the quantity on the left side $x+12$ is equal to the quantity on the right side 17' [30]. A linear equation is one that has only one real number as the solution. Thus,

$3 x-2=10$

is a linear equation while $a^{2}=9$

is not a linear equation. Therefore, a linear equation is an equation that can be expressed in the form $m x+k=0$ (11) where $m$ and $k$ are constants and $x$ is a variable [2]. The [38] places a heavy emphasis on conceptual understanding of solving linear equations within their standards. Algebra problems are often difficult for students; the transition from concrete concepts to abstract concepts is partially responsible for this difficulty [23]. Solving linear equations is a particularly important concept in algebra and one that causes confusion for students [9]. Researchers advocate the use of concrete and semi-concrete materials in mathematics education as a means of bridging the transition from concrete through semi-concrete to abstract mathematics [45], [4], [8]. Concrete materials may be purchased or improvised by teachers and students. Semi-concrete materials are drawings or diagrams that students visualise for better understanding of mathematical concepts. The general purpose of this research was to use equation models in the form of semi-concrete materials such as 'flag diagrams' and 'balance models' in solving simple linear equations to see their effect on students as they progress to use abstract way of solving simple linear equations.

\subsection{Statement of the Problem}

Students face many challenges as they learn algebra. When solving linear equations, students struggle to develop symbolic understanding [23], [40], to form an accurate meaning of the equal sign [25], and to balance conceptual and procedural knowledge [46], [48], [10]. Many students in senior high schools in Ghana are lacking in the ability to perform basic mathematical operations. They struggle with simple multiplication facts, as well as working with positive and negative numbers. These are necessary skills to have in order to succeed in solving any higher-level mathematics problem. In low level classes, teachers always use the traditional method, such as the idea of balance and the idea of transpose, in teaching how to solve linear equations, with many examples. However, their attempts are usually not very successful as students continue to make same mistakes in working with positive and negative numbers. Many students moving from junior high schools to senior high schools do not have the basic procedure in solving linear equations. They use the idea of balance and/or the idea of transpose to solve these equations and use it wrongly. With the idea of transpose, which is used by many students, they have the idea that when a positive item crosses the equal sign it changes to negative, and vice versa, and the students use the idea wrongly. Their lack of conceptual understanding prevents them from applying the method of transposing correctly and in a flexible way. After identifying these problems, the researcher thought of finding a remedy to help students in their first year in the senior high school.

\subsection{Purpose of the Study}

The purpose of this research was to find out the effect of equation models, in the form of flag diagrams and balance model, on first year senior high school students' ability to solve linear equations at Kwanyako Senior High School in Agona Kwanyako in the central region of Ghana. Kwanyako Senior High School was selected because it is among the 125-low performing senior high schools in Ghana which the Government has planned to improve their quality through a proposed [35] with a focus on mathematics and science education [35].

\subsection{Objectives of the Study}

The objectives were to:

- $\quad$ determine whether equation models can increase students' performance in solving linear equations

- $\quad$ determine the perception students have regarding equation models in the teaching and learning of how to solve linear equations.

\subsection{Research Questions}

- What misconceptions do first year senior high school students have in solving linear equations?

- What is the effect of equation models on first year senior high school students' ability to solve linear equations?

\subsection{Significance of the Study}

The findings of the study will guide teachers to vary their methodology when teaching to help students understand the concept of linear equations. The use of the equation models to solve linear equations will also motivate students; boost their confidence and interest in other related topics involving equations. The findings of the study will be of great importance to the senior high school teachers in the Agona East District of the Central Region to use equation models in teaching students for the students to grasp the concept of solving linear equations before they use the abstract ways, such as the method of balancing and the method of transposing, to solve linear equations.

\subsection{Definition of Terms}

The following are definitions of some terms that have special applications to this study. 


\subsubsection{Cognitive Science}

The interdisciplinary study of how the mind works and how students learn [51].

\subsubsection{Conceptual Understanding}

Mathematical teaching and mental constructs that focus on concepts, problem solving, and making connections [48].

\subsubsection{Intact Class}

All students in one class, learning to solve linear equations using equation models, method of balancing, and method of transposing. Concepts such as the meaning of the equal sign, inverse operations, and roles of constants, variables, and coefficients were emphasised.

\subsubsection{Constructivism}

The building of knowledge from previous knowledge structures [47].

\subsubsection{Post-positivist}

A post-positivist recognizes that the way scientists think and work and the way we think in our everyday life are not distinctly different. In post-positivist research, truth is constructed through a dialogue; valid knowledge claims emerge as conflicting interpretations and action possibilities are discussed and negotiated among the members of a community [41].

\subsubsection{Pragmatist}

Pragmatists are advocates of the approach that evaluates theories or beliefs in terms of the success of their practical application. They are practical and focused on reaching a goal. They usually have a straightforward, matter-offact approach and do not let emotion distract them,

\subsubsection{Linear Equations in One Variable}

According to [29], 'A linear equation is an equation in which variables appear as separate terms and neither variable contains an exponent other than one' (p. 355). For example, $x+5=8$

(12) $2 x=16$

(13) $2 x+5=12$

(14) $2 x+4=3 x-6$

\subsubsection{Procedural Understanding}

[48] cited by [27] defines procedural understanding as 'mathematical teaching and mental constructs that focus on algorithms, rules and procedures.'

\subsubsection{Equation Models}

Flag diagrams and balance models used in teaching how to solve linear equations in one variable.

\subsection{Delimitation of the Study}

It is not possible to test all Senior High School students in Agona East District. Thus, the study was limited to only one senior high school in the Agona East District of the Central Region, that is, Kwanyako Senior High School. Only one intact class of the first year Visual Art students was selected for the study. The study was limited to only 6 instructional days which is made up of three periods in each day with forty minutes in each period.

\section{Literature Review}

\subsection{Theoretical Framework}

An important aspect of solving equations involves having both procedural and conceptual understanding of the abstract [48], [10]. [48] provided a definition for procedural understanding, focusing on understanding symbols and rules. [48] additionally defined conceptual understanding as making connections and creating networks within information. [48] emphasised the importance of procedural knowledge and specifically addressed solving equations as an example. According to [48], there are only a few standard procedures necessary for solving equations, 'adding or subtracting from both sides, combining like terms, distributing or factoring, and multiplying or dividing both sides' (p. 409). Flexibility, according to [48], is the ability to use non-standard procedures to solve an equation in the most effective way, and is a sign of deep procedural understanding.

Not all researchers agree with [48] for example, [24] emphasised that procedural skills must be accompanied by conceptual understanding. As students learn mathematics, they need to do more than just compute; they need to understand the meaning and purpose of computations [47]. [46] discussed pitfalls in mathematics learning that develop as students focus on procedures, rather than concepts. 'Even students who do well in algebra classes often do so by treating the equations as exercises in symbol manipulation, without any connection to real-world contexts' [46].

[42] conducted research to determine how conceptual and procedural understanding affected each other among fourth and fifth grade mathematics students $(n=89)$. [42] described increases in procedural understanding as resulting from 
increased conceptual understanding. In contrast, [42] did not attribute improvements in conceptual understanding to increases in procedural understanding. As an example, [42] described students who could do arithmetic procedures such as multi-digit subtraction correctly, but did not understand conceptual ideas of mathematics such as place value. In contrast, they described students who used conceptual understanding of place value to correctly conduct mathematical procedures such as multi-digit subtraction without prior procedural knowledge.

[10], [42] claims in describing results of their quantitative study of seventh and eighth grade mathematics students $(\mathrm{n}=$ 668). More successful students were those with a higher level of conceptual knowledge. Students with conceptual knowledge were flexible in their problem-solving strategies and methods.

Constructivists advocate for active learning, which allows students to build their own conceptual understanding [15]. 'It is clear that learning is not about accumulating random information, memorising it, and then repeating it on some examination; learning is about understanding and applying concepts, constructing meaning, and thinking about ideas' [18]. When students are actively involved in teaching and learning they will build their own conceptual understanding and apply these concepts when solving equations.

According to the Cognitive Science Society, cognitive scientists aspire to understand the nature of the human mind [11]. Many cognitive scientists operate under the constructivist paradigm, which advocates student's strategy selection. Cognitive scientists expect students to develop most efficient strategies and increase understanding through this selection process [19], [46].

\subsection{Solving Equations}

According to the [13], Senior High School students need to understand how quantities are related to one another, and how algebra can be used to concisely express and analyse those relationships [13]. For example, Unit 1.8.3 of the mathematics syllabus for junior high schools states, 'students should be able to find the value of the variable for linear equations such as $x+2=5 \quad$ (16) and $2 x+3=3 x-5 \quad$ (17) [12] Unit 1.8.4 stated, 'students should be able to solve word problems involving linear equations in one variable' [12]. The [12] demonstrates that solving equations is an essential component of senior high school mathematics. Students often face challenges in mathematics content, especially when trying to make sense of abstract concepts such as solving equations. Specifically, researchers have identified three common challenges that students often face when attempting to solve equations;

- A lack of symbolic understanding of variables and coefficients within an equation [23], [40].

- A lack of understanding of the meaning of the equal sign [25] and

- A reliance on procedural knowledge without conceptual understanding [46], [48], [10].

\subsection{Meaning of the Equal Sign}

A second common difficulty for students solving equations involves interpreting the equal sign as a 'do something' sign, rather than a symbol of equality [25]. Several authors described a lack of understanding of the equal sign as a pervasive problem associated with algebra [22], [24], [43], [25]. The equal sign is ubiquitous at all levels of mathematics, but little instructional time is spent describing its meaning [25]. Without a proper understanding of equality, difficulties arise as students solve equations. Students' understanding of the equal sign was a topic of research occurring as early as the 1970s [43]. [26] conducted a study of middle school students $(n=373)$ in which they described the meaning of the equal sign within the equation, $3+4=7$ (18) Students' responses were coded as relational, operational, other, or no response. Over fifty per cent of sixth and seventh grade students reported operational responses. [26] revealed that relational responses increased as students progressed through middle school with over forty per cent of eighth graders providing a relational response. [24] stated that many students either conceptualise the equal sign as a separation of the problem and the solution, or as a left to right directional symbol for working out problems. These two misconceptions of the equal sign are problematic for solving equations because equations often include variables and constants on both sides of the equation; solving an equation does not occur from left to right. 'Many Senior High School students do not understand the meaning of the equal sign, frequently viewing the symbol as an announcement of a result of an arithmetic operation rather than as a symbol of mathematical equivalence' [25]. The authors argued that because students did not understand that the equal sign represented a relationship between two quantities, they had difficulty manipulating equations in order to find a solution. A limitation of this study was that researchers did not investigate how students developed their conception of the equal sign. A description of classroom activities may have provided insight into ways students developed these conceptions. This study is similar to the studies conducted by [3], [17], [28]. The only difference is that, they used a control group in their studies and they used only one model or method in their studies. In this study, the researcher used one intact class where majority of the students are below-average students in mathematics. The lessons were one-on-one and not through video as used by [3]. The lessons took three days instead of only 15 minutes as used by [3]. A detailed lesson note was prepared where the researcher used models ('flag diagrams' and 'balance models') to teach the students. Both conceptual and procedural methods were used in this study.

\section{Methodology}

The study used the Mixed method approach where quantitative analysis was used to compare pre-test and posttest results of the students. Qualitative analysis was also used to understand the effectiveness of the treatment as students overcame obstacles to solving simple linear equations. The quantitative and qualitative analyses complement each other; the quantitative data demonstrated differences in performances of the students while the qualitative data described these differences and provided specific examples that support claims. 


\section{1. Brief History of Mixed Methods Research}

Mixed methods research has a relatively brief history compared to quantitative and qualitative research. [50] described mixed methods research as being in its 'adolescence phase'. Like many adolescents, mixed methods researchers are in a search for identity, working to define themselves and seeking acceptance from those around them. [50] traced the roots of quantitative and qualitative research back to Antiquity as they described the informal research methods of Aristotle and other scientists. For example, the scientific assertions made by these scientists were early attempts at quantitative measurements. The passive observations made by such scientists exemplified early qualitative research.

\subsubsection{Mixed Methods Research Design}

The general purpose of this mixed methods research was to use equation models to solve simple linear equations. Specifically, the following research questions were addressed:

- What misconceptions do first year senior high school students have in solving linear equations?

- What is the effect of 'equation models' on first year senior high school students' ability to solve linear equations?

- The researcher chose to conduct a mixed methods research study, working from the Pragmatic Paradigm. Knowledge claims of pragmatists include an orientation to real-world practice and focus on a specific research problem or topic [14]. Pragmatists implement a variety of strategies of inquiry and utilize the strengths of both quantitative and qualitative methodologies. As a researcher in an education setting, quantitative strategies with random experiments were not possible. However, the researcher implemented a mixed method on an intact class. In the intact class, students' responses to and experiences with the treatment were described with qualitative methods.

- Educational research often occurs with predetermined groups by schools [14]. Within this research, one intact class of Visual Art One was used. Quantitative methods such as collecting pre-test and post-test data and using statistical analysis were used to recognise differences in students' performance. Pre-test and post-test data were compared to identify growth that occurred as a result of using the flag diagrams and the balance model.

- The value of qualitative data is the story that it tells. Quantitative data can prove a statistical difference between treatments; qualitative data can paint a picture of the differences. Qualitative data describes students' experiences, opinions and explains students' learning. Qualitative research is also beneficial for showing how things work, and how processes occur over time. According to [49], 'A primary purpose for using teaching experiment methodology is for researchers to experience, first-hand, students' mathematical learning and reasoning' (p. 267). They further described the value of educational research within the classroom, 'Looking behind what students say and do in an attempt to understand their mathematical realities is an essential part of a teaching experiment' (p. 270). The researcher wanted to know how students worked with diagrams (semiconcrete materials) and how they connected their experiences to the abstract concepts they represent. He conducted interviews with the students prior to and upon completion of the treatment.

\subsection{Population}

The target population for this study was all first year Senior High School students in the Agona East district of the Central Region of Ghana. Kwanyako Senior High School was selected for the study because Agona East District has three Senior High Schools, and Kwanyako Senior High School is the youngest and has less facilities among the three senior high schools. Also, the school is among the 125 low performing senior high schools in Ghana which the Government has planned to improve their quality through a proposed Secondary Education Improvement Project (SEIP), with a focus on mathematics and science education [35] Also, due to the geographical location of Agona Kwanyako where the Senior High School is located, students from Junior High Schools who had low grades during the Basic School Certificate Examination (B.E.C.E) are usually placed in Kwanyako Senior High School by the Computerised School Selection and Placement System (CSSPS). Even students from the localities who did not meet the placement requirement and as a result were not placed in any senior high school in Ghana, get admission to Kwanyako Senior High School. The student's demographics included $80 \%$ coming from remote villages where vehicles are not available for travelling and the students come to school by foot, and $20 \%$ are coming from towns and can be classified as middle-income class.

\subsection{Sample and Sampling Technique}

The sample for the research was restricted to the Visual Art One students of Kwanyako Senior High School in Agona Kwanyako $(N=25)$ using a purposive sampling. Purposive sampling was used because the visual art students were the weakest class among all the students doing other programmes in Kwanyako Senior High School. This is because visual art courses seem to be less difficult and weak students are usually placed to read visual art programme. The students were made up of 14 boys and 11 girls with an average age of 17 years for the boys and average age of 16 years for the girls.

The research study took place within the first four weeks of the school year in the first term after the first-year students were admitted to the Senior High School. The researcher used three weeks for the treatment. The participants in the study were in the same class, taught by the same researcher. The researcher was the head of mathematics department of the selected school for the research so he did not find it difficult to obtain approval from the school headmistress. The participants of this experiment learned to solve equations by focusing on conceptual topics such as the meaning of the equal sign, inverses, and the roles of constants and variables. The participants also learned procedures and steps for solving equations, with the additional experience of working with flag diagrams and balance models. 


\subsection{Instrumentation}

The instruments used were:

- $\quad$ Structured interview guide

- Pre-test questions

- Post-test questions

\subsection{Research Question One}

\subsubsection{Research Question One}

To answer research question one, what misconceptions do first year senior high school students have in solving linear equations? The following instruments were used; structured interview guide before pre-test, pre-test and structured interview guide after pre-test.

The structured interview guide before pre-test was made up of two structured interview questions. The first interview question was to help the researcher know whether the first-year students were taught linear equations in one variable when they were in the junior high school. The second interview question was to find out if the students really understood what the teacher taught. To help the researcher come out with some of the students' misconceptions in solving linear equations in one variable a pre-test was administered immediately after the structured interview.

The researcher administered a pre-test prior to the intervention. The pre-test was made up of five equations. The students were to solve all the five equations. Students were asked to show clearly the steps in solving the equations. The researcher designed a marking scheme with a total score of fifteen. Students were scored for correct method and accuracy according to the designed marking scheme. There were no multiple-choice questions.

The first equation in the pre-test,

$4 x+2=6 x-4$

(19) was to help the researcher find out the misconception of students on lack of understanding of the meaning of 'equal' sign, and lack of symbolic understanding of variables and coefficients.

Equations two, three, four and five in the pre-test, were used mainly to find out the reliance of students on procedural knowledge without conceptual understanding.

After the pre-test the researcher administered another structured interview to find out which equations in the pre-test students found to be difficult or not difficult. This was made up of five structured. It was to help the researcher know the level of understanding of the students on how to solve linear equations in one variable.

The researcher conducted a verbal interview after the pre-test. During the verbal interview students stated the following which were misconceptions by students:

- When a number crosses the equal sign, the sign changes. This shows a lack of understanding of the meaning of the equal sign.

- Any variable with a coefficient is taken as a number. This was clear during the pre-test where students were adding variables to numbers. This shows a lack of symbolic understanding of variables and coefficients on the part of the students.

- Always the variable must be on the left side of the equation. In the pre-test students were doing this wrongly by just bringing all variables to the left of the equation without considering the negative and the positive signs. This shows students' reliance on procedural knowledge without conceptual understanding.

\subsubsection{Research Question Two}

To answer research question two, what is the effect of 'equation models' on first year senior high school students' ability to solve linear equations? the following instruments were used; post-test and structured interview guide after posttest.

The researcher used parallel questions in the study. He used the questions in the pre-test as post-test but changed the question numbers. Students were asked to show clearly the steps in solving the equations. The same marking, with a total score of fifteen, as in the pre-test, was used. During the post-test, most students used less than thirty minutes to solve all the five equations. This showed that there was improvement in students' ability to solve linear equations in one variable after the intervention.

The researcher conducted an interview after the post-test to ascertain the effect of equation models on students' ability to solve linear equations in one variable. This was made up of seven structured questions. A verbal interview was administered immediately after the post-test structured interview.

A paired samples t-test was used to compare the results of the pre-test and the post-test to find out if there were any significant changes in students' performance in solving linear equations in one variable.

\subsection{Instructional Materials}

The researcher created a detailed lesson note as teaching and learning material for the treatment. The researcher used six periods of forty minutes per period for the intervention. The six periods were made up of two periods (80 minutes) per day. The lesson note was divided into three lessons and each lesson took 80 minutes to complete. The researcher therefore used three days to complete all the three lessons. 


\subsection{Collection of Data}

This research was conducted in a rural senior high school in the Agona East District of Central Region, Ghana. As a teacher in the school where the research was conducted the researcher took on the role of teacher-researcher for the study and used the students in his class for the study.

First year Visual Art students $(N=25)$ participated in the study during the first four weeks of the school year in the first term after the first-year students were admitted to the Senior High School. The researcher used three weeks for the treatment. Each class period lasted forty minutes.

The researcher is a 'traditional' teacher, meaning that he did not often use semi-concrete materials like flag diagrams and balance models in teaching how to solve linear equations. He was eager to see students learn with these methods and hoped to implement them into his classroom in the future and encourage other mathematics teachers to do same.

The researcher administered a pre-test to all students which included such topics as the meaning of the equal sign, the role of constants, and the role of coefficients. These equations were used for quantitative data analysis.

The students learned to solve equations by focusing on conceptual topics such as the meaning of the equal sign, inverse operations, and the roles of constants and variables. The researcher led the class discussions by discussing concepts and providing links to the real lives of students. For example, while discussing the role of the equal sign, the researcher related the equal sign to a fulcrum of a lever like a seesaw. Students shared previous experiences with a seesaw in order to see that the equal sign represents the balance point of an equation. The researcher encouraged students to actively participate and asked questions to keep students engaged. The researcher used a white marker board in front of the classroom for all diagrams in the lessons. The students started with the pre-test on the first day and post-test on the last day.

While walking around and interacting with students during lessons, the researcher asked students to explain their work and asked specific questions related to understanding solving equations, the meaning of the equal sign, and understanding of symbols.

Upon the conclusion of the treatment, the students were given a post-test in the same format as the pre-test but changed the question numbers. Students were not allowed to use flag diagrams or balance model for the post-test, but they were encouraged to create a written representation as needed. Pre-test and post-test were parallel questions.

\subsection{Data Analysis}

The data collected from the tests and interviews were analysed by conducting quantitative and qualitative statistical analysis.

The researcher compared pre-test and post-test results for the students in an attempt to determine statistically significant differences in performance between the pre-test and the post-test. This was done with the help of paired samples t-test data analysis. The data analysis was facilitated by the use of SPSS software.

\subsubsection{Research Question One}

To answer research question one, what misconceptions do first year senior high school students have in solving linear equations? the following analyses were used.

The researcher:

- Utilised the quantitative data collected from pre-test and post-test results, and the qualitative data collected from the interviews, and analysis from students work during the pre-test.

- Analysed students' interviews and all the tests using a qualitative and quantitative statistical data analysis with the help of paired samples t-test data analysis facilitated by the use of SPSS software.

- Looked at the reliance of students on written representations as they solved equations.

- Read and coded all test responses in order to identify themes and discrepant cases. Themes were developed deductively and evidence was looked for to answer the first question by reading all transcripts carefully and jotting down ideas. Students' interviews and all the tests were analysed using paired samples t-test.

After reading all transcripts again, the researcher made a list of topics; next, the topics were clustered by themes. These themes became codes and he read the transcripts again noting evidence of all themes. He developed the list below of themes that informed question one:

- Use and overuse of rules, procedures, and strategies;

- Student's knowledge of constants and variables;

- Student's knowledge of inverse operations; and

- Student's knowledge of equal sign.

The researcher looked at the qualitative data with algebraic concepts in mind.Descriptive statistics (Percentages) was used in the analysis of research question one.

\subsubsection{Research Question Two}

To answer research question two, what is the effect of equation models on first year senior high school students ability to solve linear equations? the following analyses were used; the researcher utilised the quantitative data collected from pre-test and post-test results, and the qualitative data collected from the interviews. First, the researcher conducted quantitative statistical analysis comparing pre-test and post-test results for the students in an attempt to determine statistically significant differences in performance between the pre-test and the post-test. This was done with the help of 
paired samples t-test data analysis. Data analysis was facilitated by the use of SPSS software. In addition to quantitative data analysis, the researcher analysed qualitative data collected from the interviews.

Descriptive statistics (Percentages, mean and standard deviation) and inferential statistics (paired samples t-test at $95 \%$ confidence level) were involved in the analysis of research question two.

\subsection{Summary of Research Procedures}

The purpose of this mixed methods research study was to find out the effect of 'equation models' on first year senior high school students' ability to solve linear equations at Kwanyako Senior High School in Agona Kwanyako. These students solved equations, focusing on symbolic understanding, including the equal sign, as well as developing conceptual understanding.

Quantitative and qualitative data were collected, and analysed in order to inform the research questions.

\section{Data Analyses}

\subsection{Research Question One}

To answer research question one, what misconceptions do first year senior high school students have in solving linear equations? the researcher qualitatively analysed students work looking for examples of correct and incorrect students' thinking. The students had five equations to answer. Among the students $(N=25)$, no student had all equations solved correctly. Before the pre-test, the researcher had an interview with the students on their previous knowledge in solving linear equations in one variable. All the students $(N=25)$ answered that they were taught linear equations in one variable in the Junior High School.

\begin{tabular}{|c|c|c|c|}
\hline \multicolumn{4}{|c|}{ Did you understand what the teacher taught? } \\
\hline \multirow{3}{*}{ Valid } & & Frequency & Percent \\
\cline { 2 - 4 } & Yes & 6 & 24.0 \\
\cline { 2 - 4 } & No & 19 & 76.0 \\
\cline { 2 - 4 } & Total & 25 & 100.0 \\
\hline
\end{tabular}

Table 1: Interview Result before Pre-Test

Just after the interview the researcher conducted the pre-test and had another interview after the pre-test with students to know the level of difficulty the students faced in solving the equations, and the following results were realised: Nine students (36\%) said question one was difficult whilst 16 students (64\%) said question one was not difficult

\begin{tabular}{|c|c|c|c|}
\hline \multicolumn{3}{|c|}{ Was question one difficult? } \\
\hline \multirow{3}{*}{ Valid } & & Frequency & Percent \\
\cline { 2 - 4 } & Yes & 9 & 36.0 \\
\cline { 2 - 4 } & No & 16 & 64.0 \\
\cline { 2 - 4 } & Total & 25 & 100.0 \\
\hline
\end{tabular}

Table 2: Interview Results after Pre-Test

After marking the pre-test, 6 students (24\%) had the answer to question one correct, and 19 students (76\%) had the answer to question one wrong which indicated that question one was difficult for the students.

Eight students (32\%) said question two was difficult whilst 17 students (68\%) said question two was not difficult.

\begin{tabular}{|c|c|c|c|c|c|}
\hline \multicolumn{6}{|c|}{ Was question two difficult? } \\
\hline \multirow{3}{*}{ Valid } & Yes & Frequency & Percent & Valid Percent & Cumulative Percent \\
\cline { 2 - 6 } & No & 8 & 32.0 & 32.0 & 32.0 \\
\cline { 2 - 6 } & Total & 17 & 68.0 & 68.0 & 100.0 \\
\hline
\end{tabular}

Table 3: Interview Results after Pre-Test

After marking the pre-test, one student (4\%) had the answer to question two correct, and 24 students (96\%) had the answer to question two wrong which indicated that question two was difficult for the students.

Ten students (40\%) said question three was difficult whilst 15 students (60\%) said question three was not difficult.

\begin{tabular}{|c|c|c|c|c|c|}
\hline \multicolumn{5}{|c|}{ Was question three difficult? } \\
\hline \multirow{2}{*}{ Valid } & Yes & Frequency & Percent & Valid Percent & Cumulative Percent \\
\cline { 2 - 6 } & No & 10 & 40.0 & 40.0 & 40.0 \\
\cline { 2 - 6 } & Total & 15 & 60.0 & 60.0 & 100.0 \\
\hline
\end{tabular}

Table 4: Interview Results after Pre-Test 
After marking the pre-test, the researcher realised that four students $(16 \%)$ solved question three correctly and 21 students (84\%) solved it wrongly, which indicated that question three was difficult for the students.

Question four seemed to be difficult question for the students because 17 students (68\%) said it was difficult whilst 8 students (32\%) said it was not difficult.

\begin{tabular}{|c|c|c|c|c|c|}
\hline \multicolumn{6}{|c|}{ Was question four difficult? } \\
\hline \multirow{2}{*}{ Valid } & Yes & Frequency & Percent & Valid Percent & Cumulative Percent \\
\cline { 2 - 6 } & No & 17 & 68.0 & 68.0 & 68.0 \\
\cline { 2 - 6 } & Total & 25 & 32.0 & 32.0 & 100.0 \\
\hline
\end{tabular}

Table 5: Interview Results after Pre-Test

This reflected in the students' work because 19 students (76\%) could not solve question four correctly, two students (8\%) did not attempt to solve it at all and four students (16\%) solved it correctly.

Question five appeared to be the most difficult question among the five questions and in the students interview 18 students (72\%) said it was difficult and seven students $(28 \%)$ said it was not difficult.

\begin{tabular}{|c|c|c|c|c|c|}
\hline \multicolumn{6}{|c|}{ Was question five difficult? } \\
\hline \multirow{3}{*}{ Valid } & Yes & Frequency & Percent & Valid Percent & Cumulative Percent \\
\cline { 2 - 6 } & No & 18 & 72.0 & 72.0 & 72.0 \\
\cline { 2 - 6 } & Total & 7 & 28.0 & 28.0 & 100.0 \\
\hline
\end{tabular}

Table 6: Interview Results after Pre-Test

This reflected exactly in the output of the students' solution during the pre-test. 18 students (72\%) could not solve question five correctly, three students (12\%) did not attempt to solve it at all and four students (16\%) solved it correctly. Question one was to find the students' concept of equal sign. After the pre-test the researcher realised that the students had some misconceptions on the meaning of equal sign. Students relied on rules to answer the first equation and they were wrongly using the rules. They were trying to use the transpose method but could not use it properly.

For example, a student solved question one, $4 x+2=6 x-4$

(20)

in the pre-test as follows:

$4 \mathrm{x}+2=6 \mathrm{x}-4$

$10 \mathrm{x}=2$

$10 \mathrm{x} / 10=2 / 10$

$\mathrm{x}=5$

See figure below:

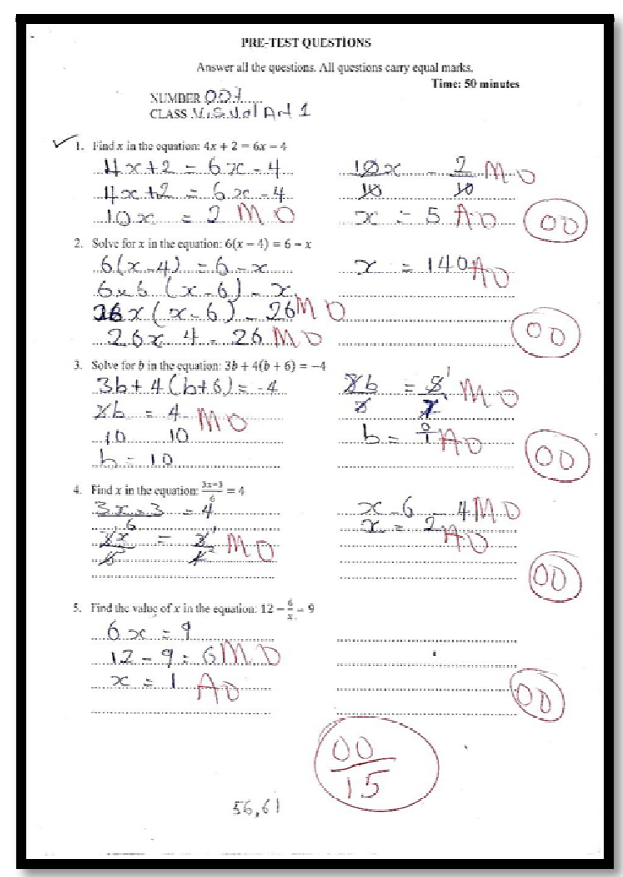

Figure 1: Pre-Test Questions

The researcher realised that students relied upon writing steps for solving equations to a greater degree in the pre-test instead of their understanding of the concept of equal sign. 
Another student solved the same question one as follows:

$4 \mathrm{x}+2=6 \mathrm{x}-4$

$4 \mathrm{x}+6 \mathrm{x}=4-2$

$10 \mathrm{x} / 10=2 / 10$

$\mathrm{x}=5$

See figure below:

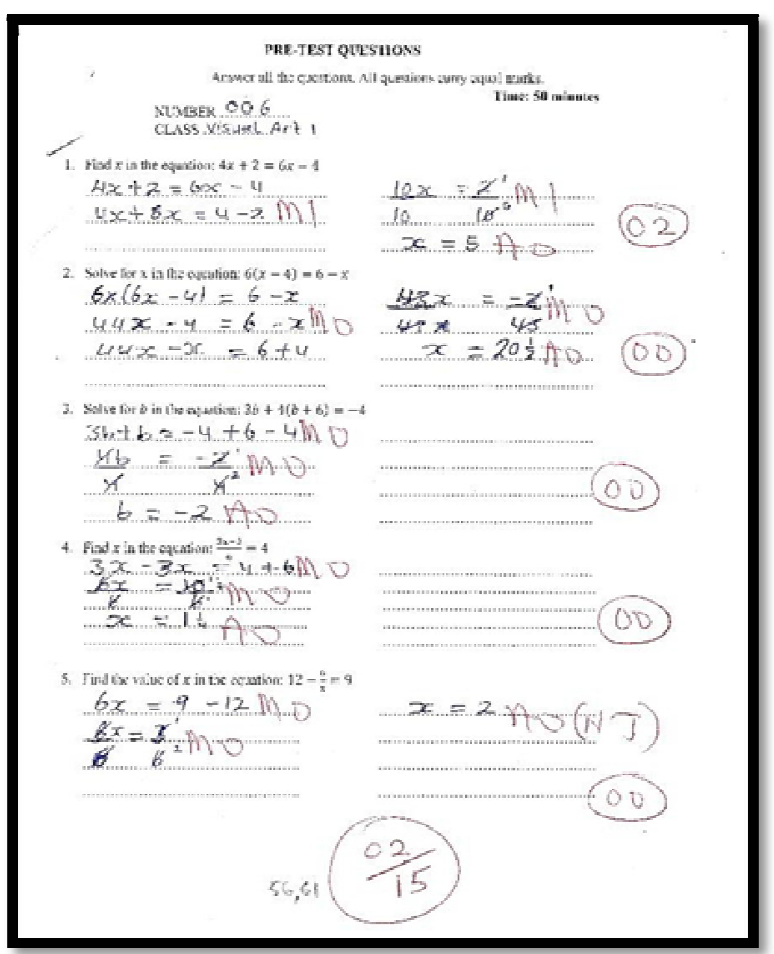

Figure 2: Pre-Test Questions

Questions two and three were to find out how students could remove brackets in a linear equation. After the pre-test the researcher realised that students were wrongly using the distributive property to solve the equation. For example, a student solved question two,

$6(x-4)=6-x$

in the pre-test as follows:

$(6 \mathrm{x}-4)=6-\mathrm{x}$

$6 \mathrm{x}-\mathrm{x}=6+4$

$5 \mathrm{x} / 5 \mathrm{x}=10 / 5 \mathrm{x}$

$\mathrm{x}=5$

See figure below:

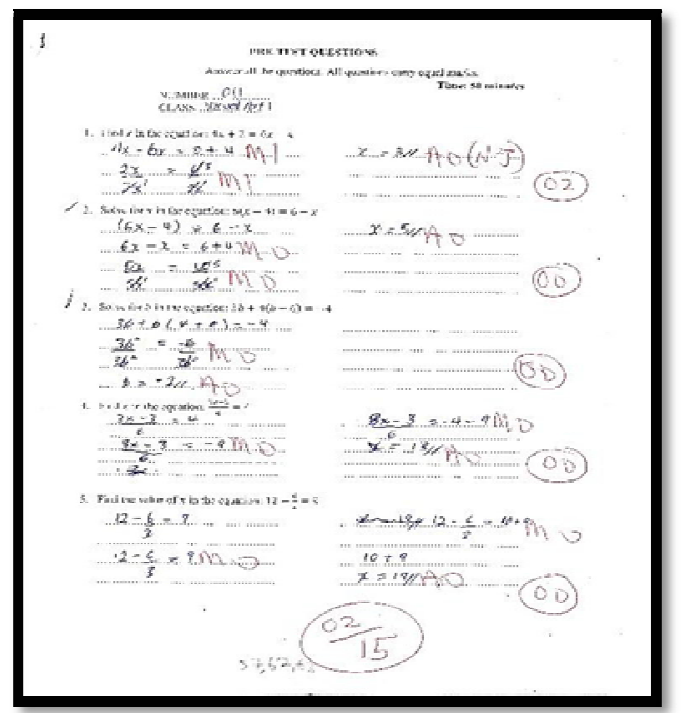

Figure 3: Pre-Test Questions 
The same student solved question three,

$3 b+4(b+6)=-4$

as follows:

$3 b+b(4+6)=-4$

$\left(3 b^{\wedge} 2\right) / \llbracket 3 b \rrbracket \wedge 2=(-6) / \llbracket 3 b \rrbracket \wedge 2$

$\mathrm{b}=-2$

See figure below:

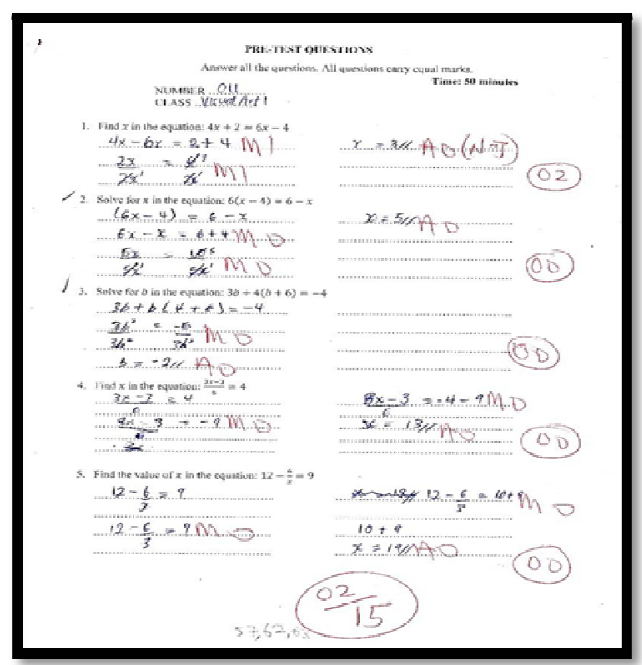

Figure 4: Pre-Test Questions

The above solution, and solutions from other students clearly showed that the students do not have any idea of expansion in solving linear equations.

Questions four and five were to test the ability of the students in clearing fractions, with a whole number as the denominator, or a variable as the denominator.

Question four,

$(3 \mathrm{x}-3) / 6=4$,

was solved in the pre-test by a student as follows:

$(6 \mathrm{x}-6) / 6=4$

$\mathrm{x} / 6=4$

$1 \mathrm{x} / 1=24 / 1$

$\mathrm{x}=24$

See figure below:

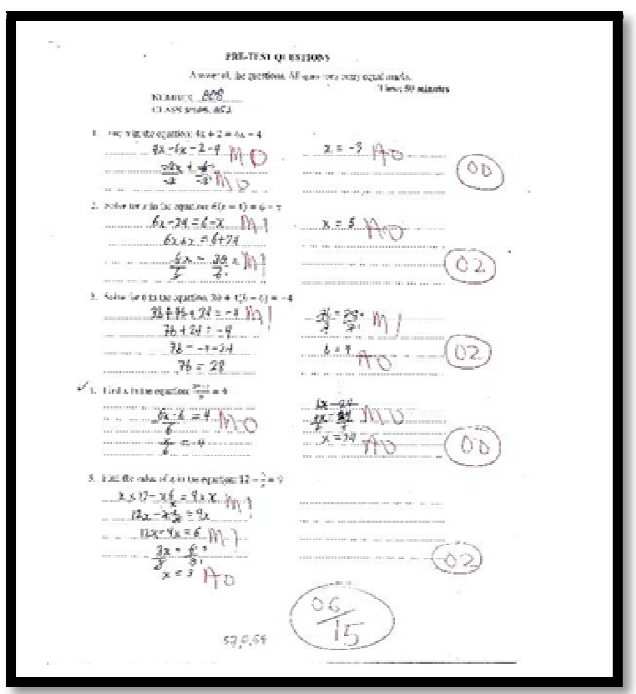

Figure 5: Pre-Test Questions

A student solved question five,

$12-6 / x=9$

(45) 
$12-6=9 x$

$6 / 9=9 x / 9$

$2 / 3=x$

$\mathrm{x}=2 / 3$

As shown in the figure below:

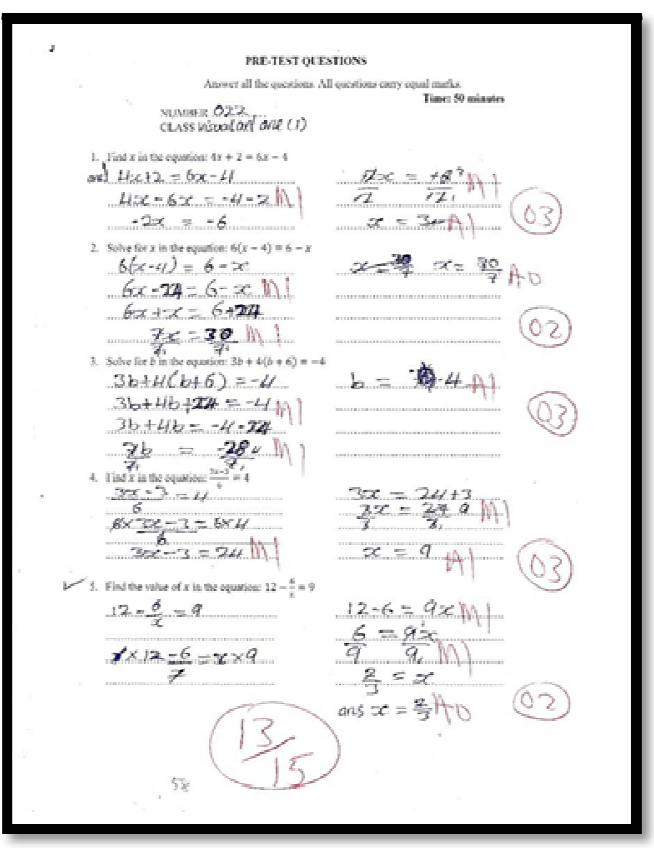

Figure 6: Pre-Test Questions

The above solution, and solutions from other students showed that students have problem with clearing fractions when solving linear equations in one variable.

From the above analysis the researcher found that the first-year senior high school students of Kwanyako Senior High School have the following misconceptions in solving linear equations; the concept of equal sign, the concept of inverse operation, the concept of distributive property and the concept of reciprocals.

\subsection{Research Question Two}

To answer research question two, what is the effect of 'equation models' on first year senior high school students' ability to solve linear equations? The researcher blended quantitative and qualitative data. He investigated qualitative and quantitative data to find the effect of flag diagrams and balance model in teaching students how to solve linear equations in one variable. This was done using paired samples t-test analysis.

The purpose of conducting a paired samples t-test was to compare the results of pre-test and post-test to see if there is any significant difference in the tests.

The paired samples t-test data analysis indicated that the pre-test scores were statistically significantly different from the post-test scores for the students. See table below.

\begin{tabular}{|c|c|c|c|c|c|c|c|c|c|}
\hline & & \multicolumn{5}{|c|}{ Paired Differences } & \multirow{3}{*}{$\mathrm{t}$} & \multirow{3}{*}{$\mathrm{df}$} & \multirow{3}{*}{$\begin{array}{l}\text { Sig. (2- } \\
\text { tailed) }\end{array}$} \\
\hline & & \multirow[t]{2}{*}{ Mean } & \multirow[t]{2}{*}{$\begin{array}{c}\text { Std. } \\
\text { Deviation }\end{array}$} & \multirow[t]{2}{*}{$\begin{array}{l}\text { Std. } \\
\text { Error } \\
\text { Mean }\end{array}$} & \multicolumn{2}{|c|}{$\begin{array}{l}\text { 95\% Confidence } \\
\text { Interval of the } \\
\text { Difference }\end{array}$} & & & \\
\hline & & & & & Lower & Upper & & & \\
\hline Pair 1 & $\begin{array}{l}\text { Pretest - } \\
\text { Posttest }\end{array}$ & -7.760 & 3.586 & .717 & -9.240 & -6.280 & -10.821 & 24 & .000 \\
\hline
\end{tabular}

Table 7: Paired Samples Test

The unique representations provided by the flag diagrams and the equation model, engagement on the part of students, and the opportunity to reflect on mathematics were benefits identified by the researcher. The necessary time for learning how to use the flag diagrams and the equation model was the observed drawback to the use of flag diagrams and the equation model for solving equations.

After working with the flag diagrams and the equation model, students were able to distinguish between coefficients and constants and realised that they were not interchangeable. For example, in the equation

$4 x+2=6 x-4(50)$ students were able to recognise that the 4xtells them how many variables were on the left side of the equation, and the 2 tells them how many constants were on the left side of the equation. They were also able to 
describe what is on the right side of the equation. This was a beneficial representation because it reflected in the work of students in the post-test.

Results of the paired samples t-test analysis indicated there is a strong evidence $(t=-10.821, p=0.000)$ that the teaching intervention improved the post-test scores. See table below.

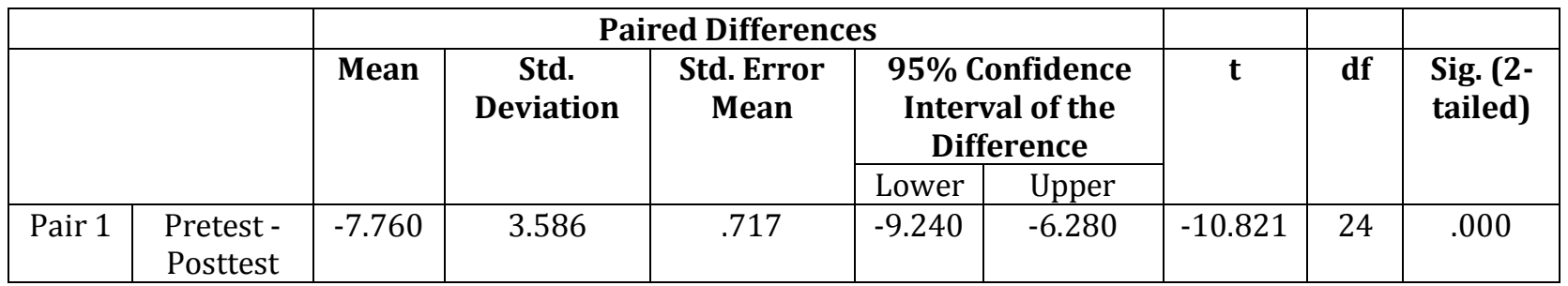

Table 8: Paired Samples Test

In this data set, it improved scores, on average, by 7.76 points. Participants experienced statistically significantly higher score in post-test $(\mathrm{p}=0.000)$ when taught how to solve linear equations using the equation models $(\mathrm{M}=12.9, \mathrm{SD}=$ 1.7 ) than in the pre-test $(M=5.12, S D=4.8)$. The $95 \%$ confidence interval for the difference is $(-9.2,-6.3)$. See table below.

\begin{tabular}{|c|c|c|c|c|c|}
\hline \multicolumn{2}{|c|}{} & Mean & N & Std. Deviation & Std. Error Mean \\
\hline \multirow{2}{*}{ Pair 1 } & Pretest & 5.12 & 25 & 4.833 & .967 \\
\cline { 2 - 6 } & Posttest & 12.88 & 25 & 1.666 & .333 \\
\hline
\end{tabular}

Table 9: Paired Samples Statistics

\subsection{Results}

The researcher conducted a post-test after the intervention and had another interview immediately after the posttest with students to know the effect of the flag diagrams and the balance model on the students in solving linear equations in one variable, and the following results were realised:

Eleven students (44\%) strongly agreed that the use of the equation models helped them to understand how to solve linear equations in one variable better, and 14 students (56\%) agreed that the use of the equation models helped them to understand how to solve linear equations in one variable better.

\begin{tabular}{|c|c|c|c|c|c|}
\hline \multicolumn{6}{|c|}{ Equation Models helped in solving equations } \\
\hline & & Frequency & Percent & Valid Percent & Cumulative Percent \\
\hline \multirow[t]{3}{*}{ Valid } & Strongly agree & 11 & 44.0 & 44.0 & 44.0 \\
\hline & Agree & 14 & 56.0 & 56.0 & 100.0 \\
\hline & Total & 25 & 100.0 & 100.0 & \\
\hline
\end{tabular}

Table 10: Post-Test Interview Results

Two students (8\%) indicated that the use of the equation model highly improved their ability in solving linear equations in one variable, and 23 students (92\%) indicated that the use of the equation model improved their ability in solving linear equations in one variable.

\begin{tabular}{|c|c|c|c|c|c|}
\hline \multicolumn{6}{|c|}{ Ability in solving linear equations } \\
\hline & & Frequency & Percent & Valid Percent & Cumulative Percent \\
\hline \multirow{3}{*}{ Valid } & Highly improved & 2 & 8.0 & 8.0 & 8.0 \\
\hline & Improved & 23 & 92.0 & 92.0 & 100.0 \\
\hline & Total & 25 & 100.0 & 100.0 & \\
\hline
\end{tabular}

Table 11: Post-Test Interview Results

Sixteen students (64\%) strongly agreed that question one was not difficult, and nine students (36\%) agreed that question one was not difficult.

\begin{tabular}{|c|c|c|c|c|c|}
\hline \multicolumn{7}{|c|}{ Question one was not difficult } \\
\hline \multirow{3}{*}{ Valid } & Strongly agree & 16 & 64.0 & 64.0 & Cumulative Percent \\
\cline { 2 - 6 } & Agree & 9 & 36.0 & 36.0 & 64.0 \\
\cline { 2 - 6 } & Total & 25 & 100.0 & 100.0 & 100.0 \\
\hline
\end{tabular}

Table 12: Post-Test Interview Results

After marking the post-test 23 students (92\%) had the answer to question one correct and two students (8\%) had the answer to question one wrong which indicates that question one really was easy for the students after the intervention. 
For example, a student who solved question one wrongly, as shown at the left side in the pre-test, solved the same question correctly at the right side in the post-test as follows:

Pre-test

$4 \mathrm{x}+2=6 \mathrm{x}-4$

$10 \mathrm{x}=2$

$10 \mathrm{x} / 10=2 / 10 \quad \mathrm{x}=5 \quad$ Post-test

$4 \mathrm{x}+2=6 \mathrm{x}-4(-2 \mathrm{x}) /(-2)=6 / 2$

$4 \mathrm{x}-6 \mathrm{x}=-4-2=\mathrm{x}=3$

$-2 x=-6$

See figure below:

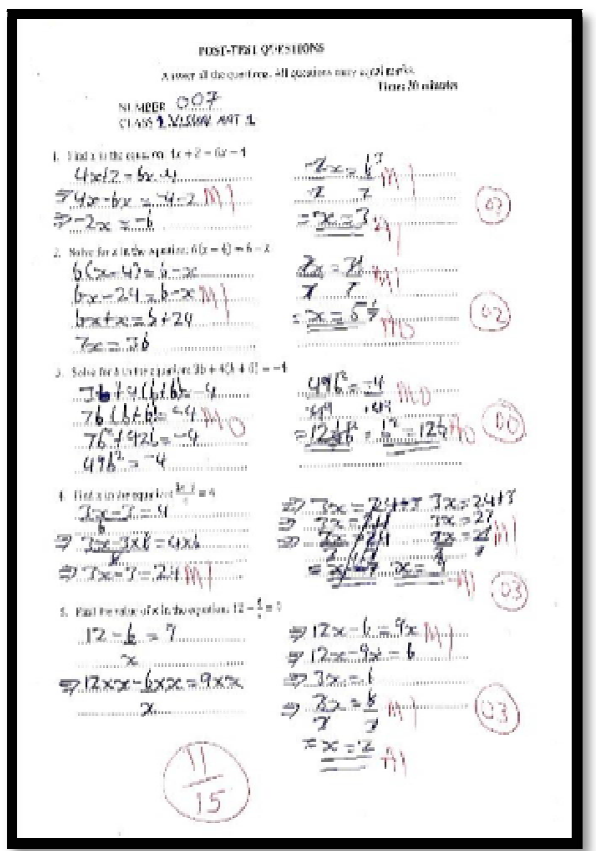

Figure 7: Post-Test Questions

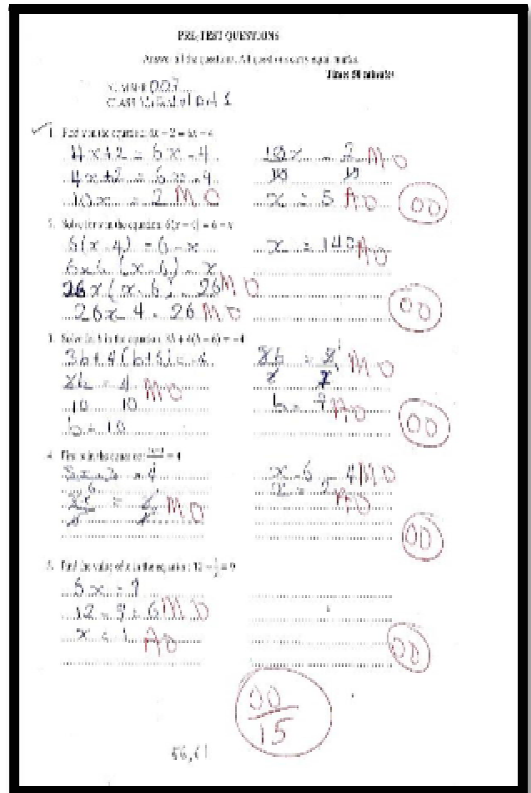

Figure 8: Post-Test Questions

below:

Another student who solved question one wrongly in the pre-test, solved it correctly in the post-test as shown

Pre-test Post-test

$4 \mathrm{x}+2=6 \mathrm{x}-44 \mathrm{x}+2=6 \mathrm{x}-4$

$4 \mathrm{x}+6 \mathrm{x}=4-24 \mathrm{x}-6 \mathrm{x}=-4-2$

$10 x / 10=2 / 10 \quad(-2 x) /(-2)=(-6) /(-2)$

$\mathrm{x}=5 \Rightarrow \mathrm{x}=3$ 
See figure below:

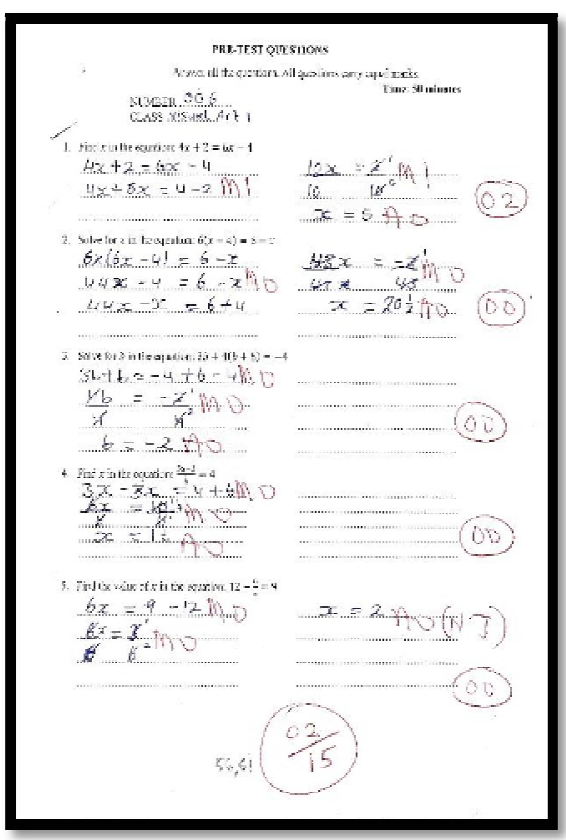

Figure 9: Post-Test Questions

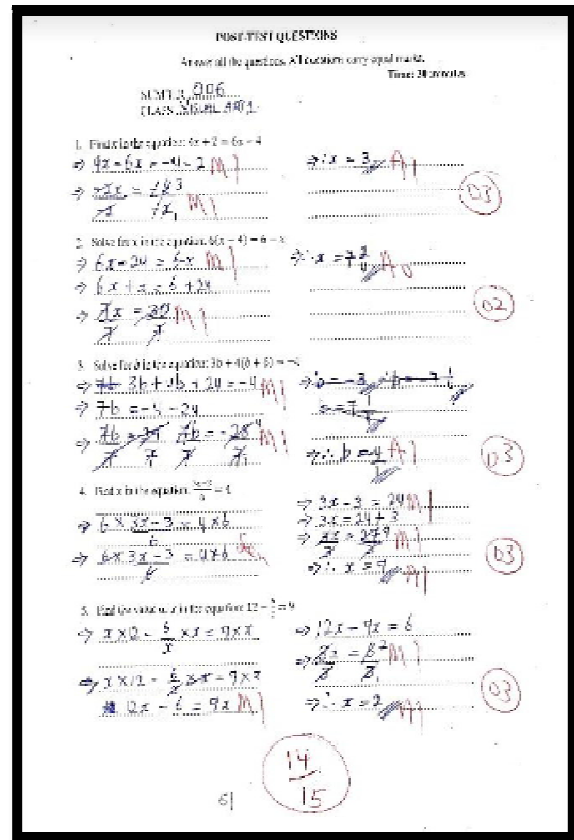

Figure 10: Post-Test Questions

Ten students (40\%) strongly agreed that question two was not difficult, and 15 students (60\%) agreed that question two was not difficult.

\begin{tabular}{|c|c|c|c|c|c|}
\hline \multicolumn{6}{|c|}{ Question two was not difficult } \\
\hline & & Frequency & Percent & Valid Percent & Cumulative Percent \\
\hline \multirow[t]{3}{*}{ Valid } & Strongly agree & 10 & 40.0 & 40.0 & 40.0 \\
\hline & Agree & 15 & 60.0 & 60.0 & 100.0 \\
\hline & Total & 25 & 100.0 & 100.0 & \\
\hline
\end{tabular}

Table 13: Post-test Interview Results

After marking the post-test, 13 students (52\%) had the answer to question two correct and 12 students (48\%) had the answer to question two wrong.

For example, a student who solved question two wrongly in the pre-test, solved the same question correctly in the posttest as follows:

Pre-test Post-test

$6(\mathrm{x}-4)=6-\mathrm{x} \quad 6(\mathrm{x}-4)=6-\mathrm{x} \mathrm{x}=30 / 7=42 / 7$ 
$(6 x-4)=6-x \quad 6 x-24=6-x$

$6 \mathrm{x}-\mathrm{x}=6+4 \quad 6 \mathrm{x}+\mathrm{x}=6+24$

$5 \mathrm{x} / 5 \mathrm{x}=10 / 5 \mathrm{x} 7 \mathrm{x}=30$

$x=57 x / 7=30 / 7$

See figure below:

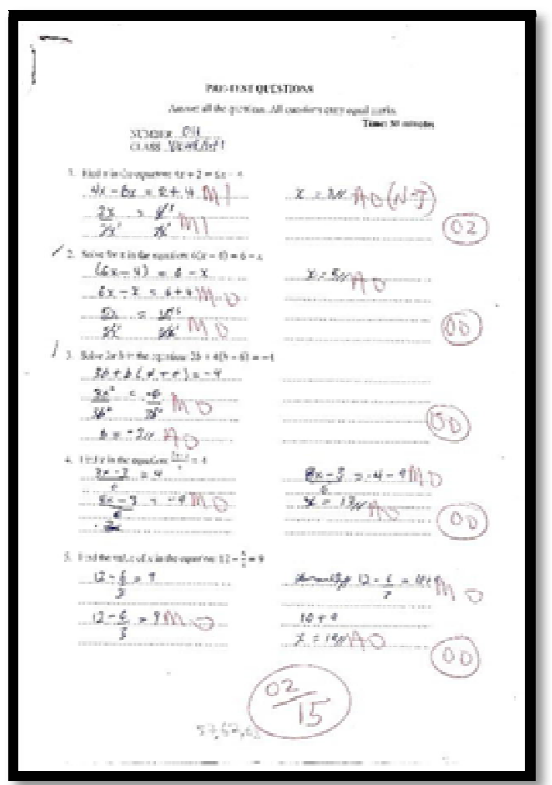

Figure 11: Post-Test Questions

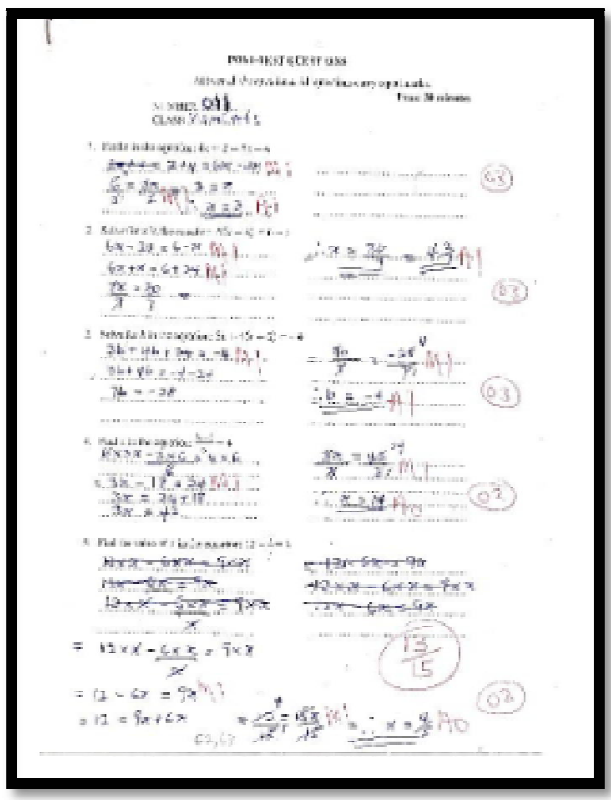

Figure 12: Post-Test Questions

Six students (24\%) strongly agreed that question three was not difficult, and 19 students (76\%) agreed that question three was not difficult.

\begin{tabular}{|c|c|c|c|c|c|}
\hline \multicolumn{7}{|c|}{ Question three was not difficult } \\
\hline \multirow{3}{*}{ Valid } & Frequency & Percent & Valid Percent & Cumulative Percent \\
\cline { 2 - 6 } & Strongly agree & 6 & 24.0 & 24.0 & 24.0 \\
\cline { 2 - 6 } & Agree & 19 & 76.0 & 76.0 & 100.0 \\
\cline { 2 - 6 } & Total & 25 & 100.0 & 100.0 & \\
\hline
\end{tabular}

Table 14: Post-Test Interview Results

After marking the post-test, 15 students (60\%) solved question three correctly and 10 students (40\%) solved it wrongly.

For example, a student who solved question three wrongly during the pre-test, solved the same question correctly during the post-test as follows: 
Pre-test Post-test

$3 b+4(b+6)=-43 b+4 b+24=-47 b / 7=(-28) / 7$

$3 b+b(4+6)=-43 b+4 b=-4-24 b=-4$

$\left(3 b^{\wedge} 2\right) / \llbracket 3 b \rrbracket \wedge 2=(-6) / \llbracket 3 b \rrbracket \wedge 2 b=-27 b=-28$

See figure below:

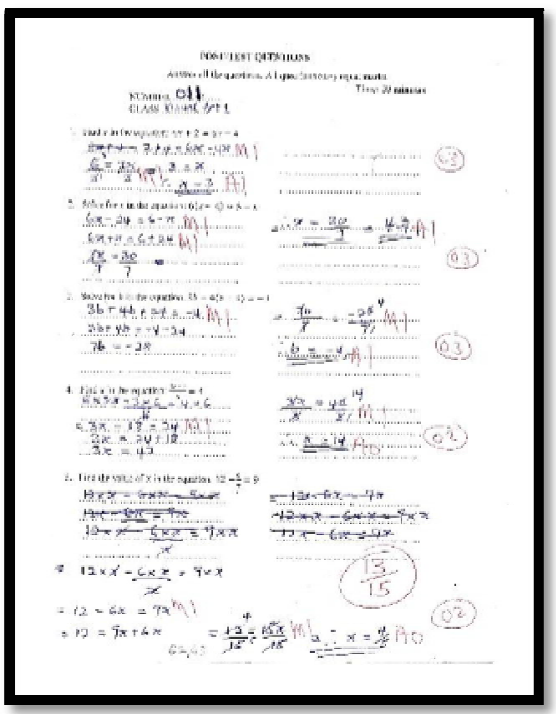

Figure 13: Post-Test Questions

Eleven students (44\%) strongly agreed that question four was not difficult, and 14 students (56\%) agreed that question four was not difficult.

\begin{tabular}{|c|c|c|c|c|c|}
\hline \multicolumn{9}{|c|}{ Question four was not difficult } \\
\hline \multirow{2}{*}{} & Frequency & Percent & Valid Percent & $\begin{array}{c}\text { Cumulative } \\
\text { Percent }\end{array}$ \\
\hline \multirow{3}{*}{ Valid } & Strongly agree & 11 & 44.0 & 44.0 & 44.0 \\
\cline { 2 - 6 } & Agree & 14 & 56.0 & 56.0 & 100.0 \\
\cline { 2 - 6 } & Total & 25 & 100.0 & 100.0 & \\
\hline
\end{tabular}

Table 15: Post-Test Interview Results

After marking the post-test, 18 students (72\%) solved question four correctly and seven students (28\%) solved it wrongly.

For example, a student who solved question four wrongly in the post-test, solved the same question correctly in the posttest as follows:

Pre-test Post-test

$(3 \mathrm{x}-3) / 6=4(3 \mathrm{x}-3) / 6=4$

$(6 \mathrm{x}-6) / 6=46((3 \mathrm{x}-3)) / 6=4 \times 6$

$\mathrm{x} / 6=43 \mathrm{x}-3=24$

$1 \mathrm{x} / 1=24 / 1 \quad 3 \mathrm{x}=24+3$

$\mathrm{x}=243 \mathrm{x}=27$

$3 x / 3=27 / 3$

$\mathrm{x}=9$

See figure below: 


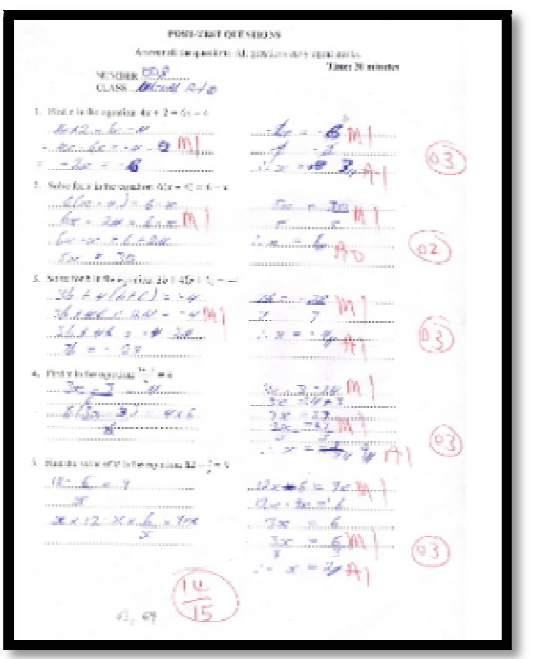

Figure 14: Post-Test Questions

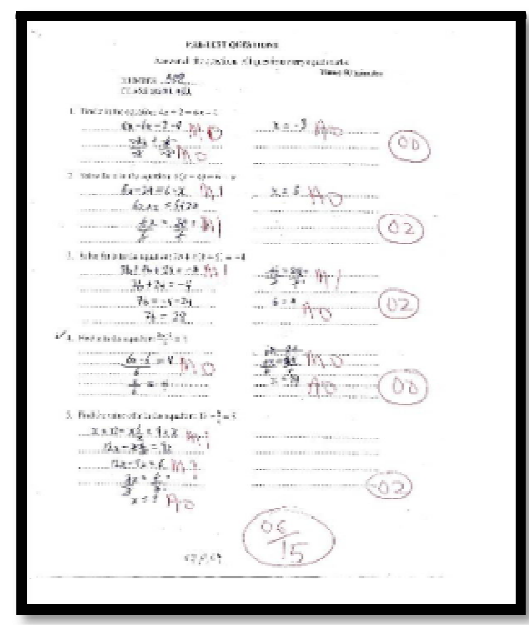

Figure 15: Post-Test Questions

Eight students (32\%) strongly agreed that question five was not difficult, and 17 students (68\%) agreed that question five was not difficult.

\begin{tabular}{|c|c|c|c|c|c|}
\hline \multicolumn{9}{|c|}{ Question five was not difficult } \\
\hline \multirow{2}{*}{} & Frequency & Percent & Valid Percent & $\begin{array}{c}\text { Cumulative } \\
\text { Percent }\end{array}$ \\
\hline \multirow{3}{*}{ Valid } & Strongly agree & 8 & 32.0 & 32.0 & 32.0 \\
\cline { 2 - 6 } & Agree & 17 & 68.0 & 68.0 & 100.0 \\
\cline { 2 - 6 } & Total & 25 & 100.0 & 100.0 & \\
\hline
\end{tabular}

Table 16: Post-test Interview Results

After marking the post-test 18 students (72\%) solved question five correctly, and seven students (28\%) could not solve it correctly.

Students did significantly well during the post-test as compared to their performance during the pre-test. This is because students developed conceptual understanding which helped them solve equations successfully during the posttest. The researcher designed the intervention such that distinct items in a form of semi-concrete diagrams represented constants, variables, and positive and negative numbers to strengthen the students' conceptual understanding of the variable, and the equal sign, after which the researcher used balancing and transpose methods to guide students to solve linear equations in one variable. This reflected in the post-test as some students used one or all the methods, except the use of the equation models, to solve the linear equations during the post-test.

The biggest challenge faced by the researcher was that students were seeing the method of using the flag diagrams and the balance method to be a waste of time until they started grasping the concepts of equal sign and the variable using the flag diagrams and the balance models.

\section{Conclusions}

The purpose of this mixed methods research was to look at the effectiveness of semi-concrete materials, such as flag diagrams and balance model, in helping students understand the concepts of the equal sign and variables when solving simple linear equations, especially when they move from the junior high school to the senior high school in rural 
communities like Kwanyako Senior High School, which is one of the 125 selected low performing senior high schools in Ghana as far as performance in mathematics is concerned.

Qualitative and quantitative methods such as interviews, pre-test and post-test were employed to inform both research questions. Paired samples t-test data analysis indicated that post-test scores were statistically significantly different from pre-test scores for the students. The researcher noted differences in learning outcomes related to representations and conceptual understanding related to the meaning of the equal sign and variables. The following were the findings from the research study:

- Unique benefits of equation models.

- Development of conceptual understanding;

- Unique representations of distinct objects within equations; and

- Use of written representations while solving linear equations;

These were evident in the result of the post-test since students did significantly well during the post-test as compared to their performance in the pre-test.

\subsection{Discussion of Findings}

According to [39], students benefit from multiple representations of topics. [31] expressed a similar view while describing students using virtual manipulatives to learn about addition. [31] suggested that manipulatives combined with a written recording of the work allow students time to reflect on the actions taken with the manipulatives. Students depended on written representations while solving equations during the post-test.

The dependence on written representations on the part of students displayed their use of rules while developing conceptual understanding of solving equations. The students developed the conceptual understanding when going through the use of flag diagrams and the equation model during the intervention lessons.

While learning to solve equations, students must develop conceptual understanding. [42] emphasized the value of conceptual understanding over procedural understanding, describing the ability of students to transfer conceptual understanding into improved procedural understanding. [42]also pointed out that the transfer does not work in reverse; rarely do students increase conceptual understanding as a result in increased procedural understanding. Constructivists such as [39], [6], [15] emphasised the important role of active learning in building meaning and understanding.[39] asserted that students must make connections and not receive facts passively.

The positive results of the students during the post-test exemplify development of conceptual understanding when they used the equation models.

In order to increase conceptual understanding, the researcher emphasised the meaning of the equal sign, and variables to the students during this research study. More students exhibited the purpose of the equal sign as a balance point on post-test than on pre-test. On pre-test, students exhibited the equal sign as a symbol of operation, or as a statement of the answer. These findings echo researchers who found elementary and middle school students struggled to accurately describe the meaning of the equal sign [25], [26].

Students should not only perform rote operations with algebraic symbols, rather they should have meaningful experiences which will develop their understanding. The students under this study experienced meaningful experiences with algebraic symbols. They experienced representations of equal sign and variables while using the flag diagrams and the balance model. [8] used cups and tiles to represent variables and constants as concrete manipulatives in a study in which eighth grade students learned to solve equations. One conclusion made by [8] was that students benefitted from the unique representations of the components of the equations. This research supported the claim because in the interview, students confirmed that the flag diagrams and the balance model were helpful in understanding the differences between variables and constants, as well as positive and negative numbers.

In this study, the researcher likened the flag diagrams and the balance model to semi-concrete materials as diagrams. Researchers disagree regarding how students should be introduced to semi-concrete materials in the classroom. [20], [4] suggested that teachers should provide students with the opportunity to play freely with diagrams prior to instruction in order to diminish their appeal as common diagrams. However, [52] strongly disagreed with this idea, stating that semi-concrete materials in diagrams should not be attractive ones, pointing to Japanese teachers who do not use novel objects as diagrams. [33] agreed with [52] stating that teachers should use diagrams that are unlike toys and avoid using items that students may consider as toys.

Some students in this study treated the diagrams as ordinary diagrams, rather than a representation of mathematics. Time was lost on learning how to use the flag diagrams and the balance model. These were some major drawbacks in this study.

Teachers must plan well while using flag diagrams and balance model in their classrooms and expect it to take additional time [20],[44], [36], [7]. Within this research study, students learned about solving equations during six instructional days at the beginning of their first year in the senior high school. Quantitative data indicated statistically significantly difference in post-test scores as compared to the pre-test scores.

Results of this study are tentative based on a small sample size and limited time frame for the study.A body of research indicates the effectiveness of concrete and semi-concrete materials [37], [7]. Some of these researchers endorsed the use of semi-concrete materials in the form of diagrams despite the fact that they did not produce statistically significant results [7].

The results of this research study indicated that flag diagrams and balance model were effective tools for helping students in solving equations as students developed conceptual understanding from it. Flag diagrams and balance model 
should not be considered a replacement for traditional learning styles; rather, flag diagrams and balance models should be considered an additional tool for students to use as they learn mathematical concepts.

One difficulty experienced by the class was cognitive overload. [21], [5] both described concerns related to the use of models. Students engage in how to solve mathematics in a traditional way and operate models at the same time, thus experiencing cognitive overload. At times, students seemed to have difficulty working with the models while making sense of equations at the same time. [34] suggested that students using models must learn material twice, once with the models, and then again with the abstract concept. This overload may have prohibited students from making connections and developing conceptual understanding. Students may have benefitted from additional time exploring the models in order to make connections.[33] described concerns related to cognitive overload resulting from the use of models stating that students can be so focused on the diagrams themselves that they entirely miss the mathematical meaning which they represent. [33] described three possible difficulties students face while using models, the first they described as nontransparency. Just because the teacher can understand the link between the models and the mathematics, the teacher should not assume that students should be able to do that as well. Second, [33] described limited cognitive resources which may be over-taxed as students use models. Finally, [33] stated that students see models as familiar objects and are unable to see them in a different role. [33] went so far as to claim that because of these reasons, models may have little impact on student learning.

First year senior high school students will be exposed to solving equations again as they get to senior high school forms two and three. Experiences and conceptual understanding developed from participating in this research study may be prior learning they may use to better understand solving linear equations later. [15] described the value of using models as previous knowledge on which new knowledge is constructed.

In conclusion, the key to learning mathematics is effectively making connections. These connections may occur in a classroom where students focus increasing conceptual understanding with models. Students must be able to make connections to previous learning experiences and real-life experiences. Students must have enough time to explore and make the mathematics meaningful to themselves. Hopefully, as these students' progress through their mathematics topics, they will remember what they learned about solving linear equations and make connections which build conceptual understanding for years to come.

\subsection{Recommendations}

After much reflection, the researcher recommends that a control group must be selected in addition to the experimental group to compare means between groups instead of one intact class. The target population should also be increased because schools in the rural areas usually have large class size. Non-parallel questions could also be used instead of parallel questions.

The researcher suggests that the use of flag diagrams and balance model should be introduced in the senior high school before students learn how to solve linear equations using the transpose method or the balancing method.

While much is known about flag diagrams and balance model, many unanswered questions still exist. Although a wealth of research exists as to the value of flag diagrams and balance model, there is much less research as to the effectiveness of flag diagrams and balance model for high school students [16], [7].

A potential area of further study related to flag diagrams and balance model is determining the effectiveness of flag diagrams and balance model for students in the junior high school. Researchers need to investigate the effect on low ability, average ability, and high ability students to see if significant differences exist. Additionally, research must take place which investigates student attitudes related to the use of flag diagrams and balance model. Clearly, flag diagrams and balance model have a valid role in mathematics education, yet many unanswered questions still exist regarding their effective usage in the classroom.

\section{References}

i. Alibali, M. W. (1999). How children change their minds: Strategy change can be gradual or abrupt. Developmental Psychology, 35, 127-145.

ii. Ampomah, A., Ansong, Y., \& Klabga, T. K. (2009). Enriched Mathematics for Senior High Schools, S.H.S. 1, pages 182 $-188$.

iii. Araya, R., Calfucura, P., Jiménez, A., Aguirre, C., Palavicino, A. M., Lacourly, N. (2010). The effect of analogies on learning to solve algebraic equations. Pedagogies: An International Journal, 5(3), 216-232.

iv. Boggan, M., Harper, S., \& Whitmire, A. (2010). Using manipulatives to teach elementary mathematics. Journal of Instructional Pedagogies, 3, 1-6.

v. Borenson, H., \& Barber, L. (2008). The effect of hands-on equations on the learning of Algebra by 6th, 7th, and 8th grade inner city students. Retrieved from http://www.borenson.com/Portals/25/Interim10ReportDec010-20086th7th8th-innercity.pdf

vi. Bruner, J. (1960). The Process of Education. Cambridge, MA: Harvard University Press.

vii. Burns, B. A., \& Hamm, E. M. (2011). A comparison of concrete and virtual manipulative use in third- and fourthgrade mathematics. School Science and Mathematics 111, 256- 261.

viii. Caglayan, G., \& Olive, J. (2010). Eighth grade students' representations of linear equations on a cups and tiles model. Educational Studies in Mathematics, 74, 143-162. doi:10.1007/s10649-010-9231-z

ix. Cai, J., \& Moyer, P. (2008). Developing algebraic thinking in earlier grades: Some insights from international comparative studies. In C. E. Greenes (Ed.), Algebra and algebraic thinking in school mathematics. 169-179. Reston, VA: National Council of Teachers of Mathematics. 
x. Capraro, M. M., \& Joffrion, H. (2006). Algebraic equations: Can middle-school students meaningfully translate from words to mathematical symbols? Reading Psychology, 27, 147-164.doi: 10.1080/02702710600642467.

xi. Cognitive Science Society. (2011). Retrieved from http://cognitivesciencesociety.org/index.html.

xii. CRDD. (2010). National Syllabus for Mathematics (Junior High School 1-3). Page 15.

xiii. CRDD. (2012). National Syllabus for Mathematics (Junior High School 1-3). Pages 34-35.

xiv. Creswell, J. W. (2003). Research design: Qualitative, quantitative, and mixed methods approaches. Thousand Oaks, CA:

xV. Ernest, P. (1996). Varieties of constructivism: A framework for comparison. In L. P. Steffe, P. Nesher, P. Cobb, G. A. Goldin, \& B. Greer (Eds.), Theories of mathematical learning (pp. 389-398). Hillsdale, NJ: Erlbaum.

xvi. Freer-Weiss, D.M. (2006). Keep the rationale for using manipulatives in the middle grades. Mathematics Teaching in the Middle School, 11, 238 - 242.

xvii. Ganyoh, L. A. (2012). Using Balanced Scale Model Approach to Alleviate the Conceptual Problem Faced by Form 1 Visual Arts Students of Anum Presbyterian Senior High School in Solving Linear Equations in One Variable.

xviii. Gordon, M. (2009). The misuses and effective uses of constructivist teaching. Teachers and Teaching: Theory and Practice, 15, 737-746.

xix. Hatano, G. (1996). A conception of knowledge acquisition and its implications for mathematics education. In L. Steffe (Ed.), Theories of mathematical learning (pp. 197-218). Mahwah, NJ: Erlbaum.

xx. Johnson, K.A. (1993). Manipulatives allow everyone to learn mathematics. Contemporary Education. 65, 10 - 11.

xxi. Kaput, J. J. (1992). Technology and mathematics education. In D. Grouws (Ed.), Handbook of research on mathematics teaching and learning. New York: Macmillan Library References.

xxii. Kieran, C. (1992). The learning and teaching of school algebra. In D. Grouws (Ed.), Handbook of research on mathematics teaching and learning. New York: Macmillan Library Reference.

xxiii. Kilpatrick, J., \& Izsak, A. (2008). A history of algebra in the school curriculum. In C. E. Greenes (Ed.), Algebra and algebraic thinking in school mathematics (pp. 3-18). Reston, VA: National Council of Teachers of Mathematics.

xxiv. Kilpatrick, J., Swafford, J., \& Findell, B. (2001). Adding it up: Helping children learn mathematics. Washington D.C.: National Academy Press.

xxv. Knuth, E. J., Stephens, A. C., McNeil, N. M., \& Alibali, M. W. (2006). Does understanding the equal sign matter? Evidence from solving equations. Journal of Research in Mathematics Education, 37(4), 297-312.

xxvi. Knuth, E.J., Alibali, M. W., McNeil, N. M., Weinberg, A., \& Stephens, A.S. (2005). Middle school students' understanding of core algebraic concepts: Equality \& variable. Zentralblatt fur Didaktik der Mathematik [International Reviews on Mathematical Education], 37, 68-76.

xxvii. Magruder, R. L. (2012). Solving Linear Equations: A comparison of Concrete and Virtual Manipulatives in Middle School Mathematics.

xxviii. Mainu, J. K. (2012). Improving Students' Performance in Solving Linear Equations in One Variable at Konadu Yiadom Senior High School Using the Balance Model.

xxix. Malloy, C. E., Molix-Bailey, R. J., Price, J., \& Willard, T. (2008). Pre-Algebra. New York: McGraw Hill Glencoe.

xxx. Martin, J. L., Afful, E., Mereku, D. K., Appronti, D. O., Duedu, C. (1994). Mathematics for Teacher Training in Ghana. Unimax Publishers Limited.

xxxi. Martin, T. (2008). Physically distributed learning with virtual manipulatives for elementary mathematics. In D. H. Robinson, \& G. Schraw (Eds.), Recent innovations in educational technology that facilitate student learning.253275. Charlotte, NC: Information Age Publishing.

xxxii. McNeil, N. M., Grandau, E. L., Knuth, E. J., Alibali, M. W., Stephens, A. S., Hattikudur, S., \& Krill, D. (2006). Middleschool students' understanding of the equal sign: The books they read can't help. Cognition \& Instruction, 24(3), 367-385.

McNeil, N.M., \& Jarvin, L. (2007). When theories don't add up: Disentangling the manipulatives debate. Theory into Practice. 46, 309 - 316.

xxxiii. McNeil, N. M., \& Uttal, D. H. (2009). Rethinking the use of concrete materials in learning: Perspectives from development and education. Child Development Perspectives, 3, 137-139.

xxxiv. Ministry of Education, Secondary Education Improvement Project. (2014). Project Implementation Manual. Ghana: Secondary Education Improvement Project.

xxxv. Moyer, P., Bolyard, J. J., \& Spikell, M. A. (2002). What are virtual manipulatives? Teaching Children Mathematics, 372-377.

xxxvi. Moyer-Packenham, P. S., Salkind, G., \& Bolyard, J. J. (2008). Virtual manipulatives used by K-8 teachers for mathematics instruction: Considering mathematical, cognitive, and pedagogical fidelity. Contemporary Issues in Technology and Teacher Education. 8, $202-218$.

xxxvii. National Council of Teachers of Mathematics (2010). Principles and standards for school mathematics. Reston, VA: National Council of Teachers of Mathematics.

xxxviii. Piaget, J. (1926). The language and thought of the child. New York, NY: Harcourt, Brace \& Company.

xxxix. Poon, K., \& Leung, C. (2010). Pilot study on algebra learning among junior secondary students. International Journal of Mathematics Education in Science and Technology, 41, 49- 62.

xl. Ritchie, S. M., \& Rigano, D. L. (2001). Researcher-participant positioning in classroom research. International Journal of Qualitative Studies in Education, 14, 752.

xli. Rittle-Johnson, B. \& Alibali, M. W. (1999). Conceptual and procedural knowledge of mathematics: Does one lead to another? Journal of Educational Psychology, 9, 175 - 189. 
xlii. Rojano, T. (2002). Mathematics learning in the junior secondary school: Students' access to significant mathematical ideas. In L. English (Ed.), Handbook of international research in mathematics education. Mahwah, NJ: Lawrence Erlbaum Associates.

xliii. Ross, R., \& Kurtz, R. (1993). Making manipulatives work: A strategy for success. The Arithmetic Teacher, 40, 254 257.

xliv. Sherman, J., \& Bisanz, J. (2009). Equivalence in symbolic and nonsymbolic contexts: Benefits of solving problems with manipulatives. Journal of Educational Psychology, 101, 88- 100.

xlv. Siegler, R. S. (2003) Implications of cognitive science research for mathematics education. In J. Kilpatrick, W. B. Martin, \& D. E. Schiftler, (Eds.), A research companion to principles and standards for school mathematics. 219233. Reston, VA: National Council of Teachers of Mathematics.

xlvi. Sriraman, B., \& Lesh, R. (2007). A conversation with Zoltan Dienes. Mathematical Thinking and Learning, 9(1), 5975.

xlvii. [48] Star, J. R. (2005). Reconceptualising procedural knowledge. Journal of Research in Mathematics Education, 36, 404-411.

xlviii. Steffe, L. P., Thompson, P. W., \& vonGlaserfeld, E. (2000). Teaching experiment methodology: Underlying principles and essential elements. In Kelly, A. \& R. Lesh (Eds.) Handbook of research design in mathematics and science education. 267- 306. Mahwah, NJ: Erlbaum.

xlix. Teddle, C., \& Tashakkori, A. (2009). Foundations of mixed methods research: Integrating quantitative and qualitative approaches in the social and behavioral sciences. Thousand Oaks, CA: Sage Publications.

l. Thompson, P. (1996). Imagery and the development of mathematical reasoning. In L. Steffe (Ed.), Theories of mathematical learning (pp. 267-283). Mahwah, NJ: Erlbaum.

li. Uttal, D., Scudder, K. V., \& Deloache, J. S. (1997). Manipulatives as symbols: A new Perspective on the use of concrete objects to teach mathematics. Journal of Applied Developmental Psychology, 18, 37-54. 